06

\title{
Получение пленки оксида железа на сапфировой подложке
}

\author{
() Ю.В. Клунникова, С.П. Малюков, А.В. Саенко, Д.А. Сарычев, \\ В.В. Китаев
}

Южный фредеральный университет, Ростов-на-Дону, Россия

E-mail: yvklunnikova@sfedu.ru

Поступило в Редакцию 28 июля 2017 г.

Получены пленки оксида железа на сапфировой подложке с применением лазерного излучения (длина волны $1064 \mathrm{~nm}$ ). Структура поверхности пленки исследовалась с помощью сканирующего электронного микроскопа. Проведены исследования пленки методом трансмиссионной мессбауэровской спектроскопии. Полученные пленки $\mathrm{Fe}_{2} \mathrm{O}_{3}$ находятся предположительно в суперпарамагнитном состоянии, что может найти широкое применение для газочувствительных сенсоров и различных магнитных устройств.

DOI: 10.21883/PJTF.2018.12.46293.16989

Получение пленок на сапфировой подложке с использованием коротковолнового высокопроизводительного излучения является эффективной заменой высокотемпературному отжигу в муфельной печи.

Использование сапфировой подложки при получении пленок с применением лазерного излучения обусловлено рядом технико-физических свойств данного материала (диэлектрические свойства, устойчивость к механическим воздействиям, температурам, излучению) [1,2]. Формирование пленок на поверхности сапфира лазерным излучением позволяет избежать некоторых технических недостатков, а именно размягчения подложки и в конечном счете разрушения данной пленки.

Базовым элементом большинства устройств электроники являются высококачественные тонкие пленки и пленочные структуры, сформированные на подложках, характеризуемых определенным набором свойств. Пленки на сапфировой подложке могут быть весьма полезными при создании новых газочувствительных датчиков и специальных тонкопленочных покрытий топливных элементов, сочетающих в себе свойства катализаторов и проводящих элементов, защитных покрытий, устройств тонкопленочной оптоэлектроники. 
Современные полупроводниковые технологии и в первую очередь микро- и оптоэлектроника требуют не только совершенствования известных (термический отжиг в муфельных печах, химическое травление), но и создания принципиально новых технологических методов. К их числу относятся лазерный отжиг и лазерная абляция полупроводников.

Задачей настоящей работы являются формирование и исследование свойств пленки оксида железа на сапфировой подложке с применением лазерного излучения.

Воздействие инфракрасным $\mathrm{Nd}$ :YAG-лазером (длина волны $1064 \mathrm{~nm}$, мощность лазерного излучения $90 \mathrm{~W}$, время обработки 30-40 s) на границу раздела сапфировая подложка/поглощающая жидкость $\mathrm{FeCl}_{3}$ в специально оборудованном алюминиевом кожухе позволило получить пленку оксида железа на поверхности сапфировой подложки.

Структура поверхности образцов исследовалась с помощью сканирующего электронного микроскопа (FE-SEM) Hitachi SU8000 в Институте органической химии им. Н.Д. Зелинского РАН (Москва) [2,3]. Для съемки образцы располагались на поверхности алюминиевого столика с диаметром $25 \mathrm{~mm}$, крепились с помощью проводящего клея и на них напылялся проводящий слой металла ( $\mathrm{Pt} / \mathrm{Pd}$ в соотношении 80/20) толщиной $6 \mathrm{~nm}$ методом магнетронного распыления, описанным в работах $[4,5]$. Получение изображений осуществлялось в режиме регистрации вторичных электронов при ускоряющем напряжении $10 \mathrm{kV}$ и рабочем расстоянии 8-18 mm. Морфология образцов изучалась с учетом поправки на поверхностные эффекты напыления проводящего слоя [5].

Проведено EDX-SEM-исследование (EDX - энергодисперсионная рентгеновская спектроскопия, SEM - растровая электронная микроскопия) образцов и их картографирование с помощью энергодисперсионного спектрометра Oxford Instruments X max. До измерения образцы покрывались тонкой пленкой палладия $(6 \mathrm{~nm})$ с помощью углеродного напылителя Cressington 208.

На рис. 1, $a, b$ представлена морфология нерастворимой в воде пленки $\mathrm{Fe}_{2} \mathrm{O}_{3}$ на поверхности сапфировой подложки, полученной при многократной обработке пластины (четыре прохода) $\mathrm{Nd}$ :YAG-лазером с мощностью $96 \mathrm{~W}$ в растворе $3 \% \mathrm{FeCl}_{3}$. На рис. 2 представлены массспектры полученного образца.

Полученные пленки исследовались с использованием мессбауэровского спектрометра MS1104EM, разработанного Научно-

Письма в ЖТФ, 2018, том 44, вып. 12 

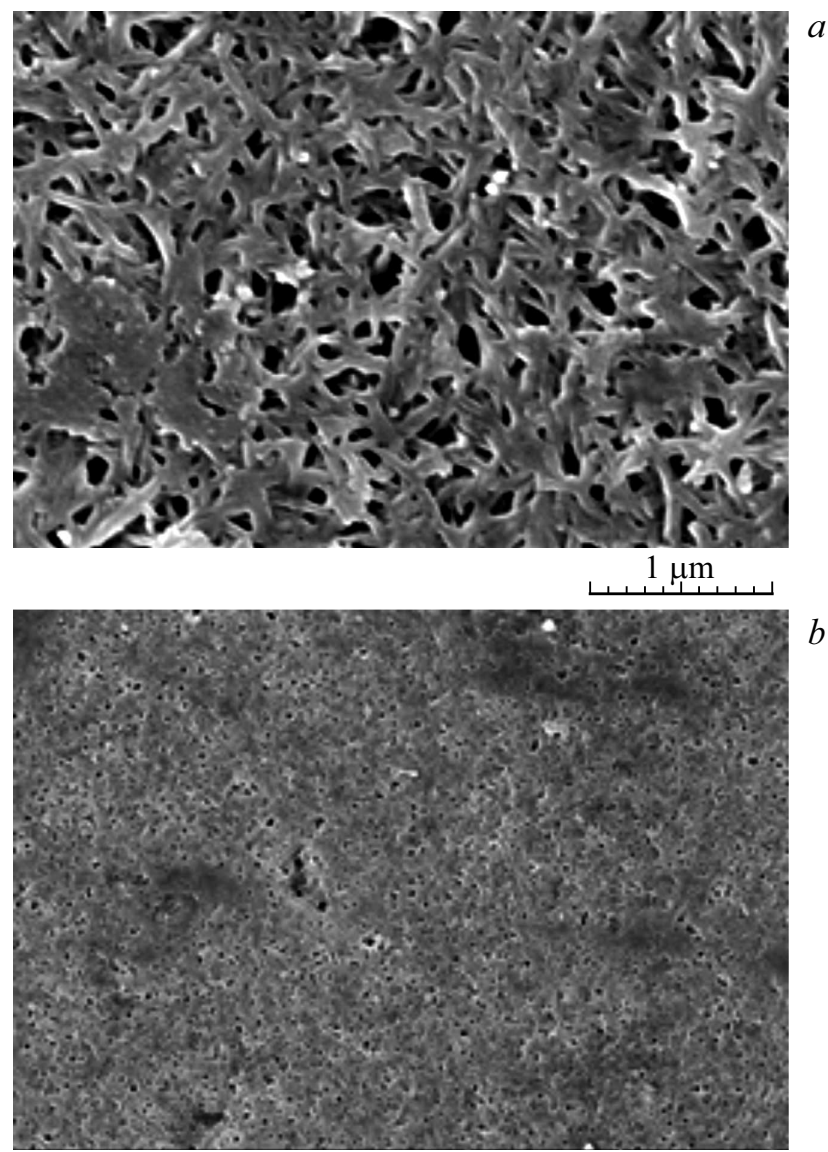

$10 \mu \mathrm{m}$

Рис. 1. Изображения поверхности пленки $\mathrm{Fe}_{2} \mathrm{O}_{3}$ на сапфировой подложке.

исследовательским институтом физики Южного федерального университета [6]. Первоначальная толщина сапфировой подложки составляла около $3 \mathrm{~mm}$, что являлось препятствием для проведения трансмиссионных измерений в связи с практически полным поглощением мессбауэровского излучения на резонансе ${ }^{57} \mathrm{Fe}$ в материале подложки. По-

Письма в ЖТФ, 2018, том 44, вып. 12 


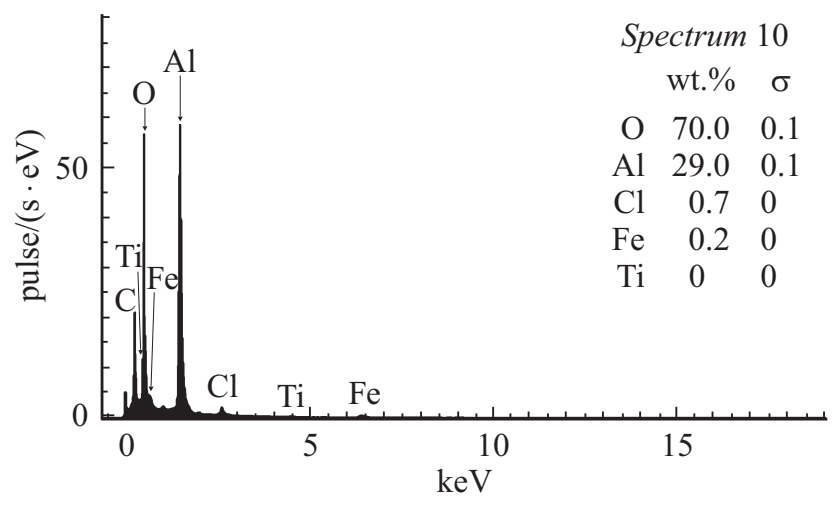

Рис. 2. Масс-спектры полученного образца.

этому была предпринята попытка измерения спектра с использованием проточной камеры для регистрации электронов внутренней конверсии типа CEMDU-4. Однако в связи с малой толщиной исследуемой пленки измерения, проведенные в течение $54 \mathrm{~h}$, не позволили получить статистически значимые результаты и определить фазовое и магнитное состояние образца.

Для проведения трансмиссионных измерений была выполнена шлифовка сапфировой подложки со стороны, противоположной имеющейся пленке, и ее толщина была уменьшена до $1 \mathrm{~mm}$, что обеспечивало около $25 \%$ пропускания мессбауэровской линии излучения источника и позволяло за несколько суток измерений накопить спектр, достаточный для оценки параметров линий резонансного поглощения.

Измерения проводились в течение $74 \mathrm{~h}$ при температуре $300 \mathrm{~K}$ в геометрии с перемещаемым образцом и неподвижным источником (источник ${ }^{57} \mathrm{Co}$ в матрице $\mathrm{Rh}$, активность $40 \mathrm{mCi}$, детектор сцинтилляционный с кристаллом $\mathrm{NaI}(\mathrm{Tl})$ толщиной $0.1 \mathrm{~mm}$, энергия гамма-квантов $14.4 \mathrm{keV})$. Измерения осуществлялись при „треугольном“ режиме работы модулятора (с постоянным ускорением) с числом точек мессбауэровского спектра 1024. Спектры прямого и обратного хода суммировались. Погрешности суммирования составили менее 0.5 канала. На рис. 3 представлен трансмиссионный мессбауэровский спектр исследуемого образца.

Письма в ЖТФ, 2018, том 44, вып. 12 


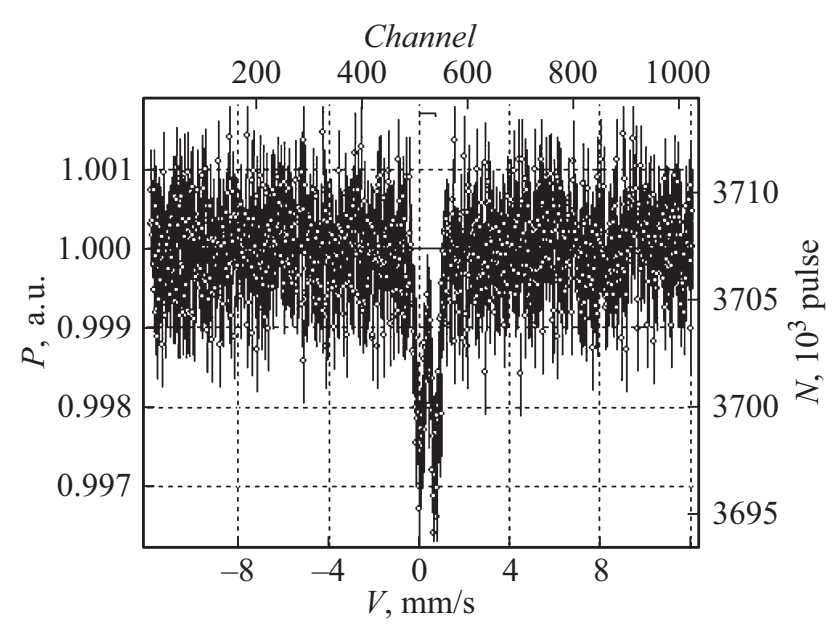

Рис. 3. Трансмиссионный мессбауэровский спектр исследуемого образца.

На трансмиссионном ${ }^{57} \mathrm{Fe}$ мессбауэровском спектре исследуемого образца наблюдаются уширенные дублетные линии. Величина ширины линии дублета $G \approx 0.70 \pm 0.02 \mathrm{~mm} / \mathrm{s}$. Величина изомерного сдвига дублета составляет $\delta \approx 0.37 \pm 0.02 \mathrm{~mm} / \mathrm{s}$ и соответствует ионам $\mathrm{Fe}^{3+}$ [7]. Величина квадрупольного расщепления $\Delta \approx 0.67 \pm 0.02 \mathrm{~mm} / \mathrm{s}$. Параметры дублета по значениям близки к параметрам, наблюдаемым для наночастиц гематита [8-11]. Появление парамагнитного дублета в гематите при температурах ниже температур магнитных фазовых переходов обусловлено возникновением суперпарамагнитной релаксации [12]. Суперпарамагнетизм в гематите проявляется при размерах кристаллитов $<200 \mathrm{~nm}$ и вследствие высокой частоты релаксации магнитных моментов $\mathrm{Fe}^{3+}$ приводит к схлопыванию зеемановской структуры мессбауэровского спектра [13]. Таким образом, с большой долей вероятности можно предположить, что наблюдаемый дублет на мессбауэровском спектре образца соответствует $\alpha-\mathrm{Fe}_{2} \mathrm{O}_{3}$ в суперпарамагнитном состоянии.

На основании проведенных исследований выявлено, что с помощью использованной авторами технологии на поверхности сапфировой подложки получены однородные пленки оксида железа $\left(\mathrm{Fe}_{2} \mathrm{O}_{3}\right)$ толщиной порядка нескольких микрометров. Оксиды железа всегда являются 
основой магнитных процессов, которые позволяют применять их в различных магнитных устройствах.

Проведены исследования воздействия лазерного облучения на пленкообразующий раствор, получены и исследованы пленки оксида железа $\left(\mathrm{Fe}_{2} \mathrm{O}_{3}\right)$. Данные исследования позволили предположить, что с помощью лазерного облучения пленкообразующих растворов можно формировать различные пленки. В частности, авторами получены пленки диоксида титана $\left(\mathrm{TiO}_{2}\right)$ и оксида марганца $\left(\mathrm{MnO}_{2}\right)$ на сапфировой и стеклянной подложках, которые могут быть использованы в качестве чувствительных материалов газовых сенсоров для оповещения о пожаре, обнаружения концентраций опасных, токсичных и вредных веществ.

Работа выполнена при финансовой поддержке Министерства образования и науки РФ (проект № 14.587.21.0025, уникальный идентификатор проекта RFMEF158716X0025).

\section{Список литературы}

[1] Dobrovinskaya E.R., Lytvynov L.A., Pishchik V.V. Sapphire: material, manufacturing, applications. Berlin: Springer, 2009. $481 \mathrm{p}$.

[2] Malyukov S.P., Klunnikova Y.V., Sayenko A.V. // J. Russ. Laser Res. 2015. V. 36. N 3. P. $276-280$.

[3] Malyukov S.P., Klunnikova Y.V. // Advanced Materials: studies and applications. Nova Sci. Publ., 2015. P. 65-75.

[4] Качала В.В., Хемчян Л.Л., Кашин А.С., Орлов Н.В., Грачев А.А., Залесский С.С., Анаников В.П. // Успехи химии. 2013. Т. 82. N 7. С. 648-685.

[5] Кашин А.С., Анаников В.П. // Изв. АН. Сер. хим. 2011. № 12. С. 2551-2556.

[6] Kitaev V.V., Rogozev B.I., Christich S.V., Sarychev D.A. // Int. Conf. „Mössbauer spectroscopy and its applications“. St. Petersburg, 2002. P. 211.

[7] Menil F. // J. Phys. Chem. Solids. 1985. V. 46. N 7. P. 763-789.

[8] Kündig W., Bömmelf H., Constabaris G., Lindqutst R.H. // Phys. Rev. 1966. V. 142. N 2. P. 327-333.

[9] Liu M., Li H., Xiao L., Yu W., Lu Y., Zhao Z. // J. Magn. Magn. Mater. 2005. V. 294. N 3. P. 294-297.

[10] Rancourt D.G., Julian S.R., Daniels J.M. // J. Magn. Magn. Mater. 1985. V. 49. N 3. P. 305-316.

[11] Hansen M.F., Koch C.B., Mфrup S. // Phys. Rev. B. 2000. V. 62. N 2. P. 1124 1135.

[12] Bedanta S., Kleemann W. // J. Phys. D: Appl. Phys. 2009. V. 42. N 1. P. 013001.

[13] Mфrup S., Brok E., Frandsen C. // J. Nanomater. 2013. V. 2013. P. 720629 (1-8).

Письма в ЖТФ, 2018, том 44, вып. 12 